IZA DP No. 10082

Worth the Wait? The Effect of Early Term Birth on Maternal and Infant Health

Kasey Buckles

Melanie Guldi

July 2016 


\title{
Worth the Wait? \\ The Effect of Early Term Birth on Maternal and Infant Health
}

\author{
Kasey Buckles \\ University of Notre Dame, \\ NBER and IZA \\ Melanie Guldi \\ University of Central Florida
}

Discussion Paper No. 10082

July 2016

IZA

P.O. Box 7240

53072 Bonn

Germany

Phone: +49-228-3894-0

Fax: +49-228-3894-180

E-mail: iza@iza.org

Any opinions expressed here are those of the author(s) and not those of IZA. Research published in this series may include views on policy, but the institute itself takes no institutional policy positions. The IZA research network is committed to the IZA Guiding Principles of Research Integrity.

The Institute for the Study of Labor (IZA) in Bonn is a local and virtual international research center and a place of communication between science, politics and business. IZA is an independent nonprofit organization supported by Deutsche Post Foundation. The center is associated with the University of Bonn and offers a stimulating research environment through its international network, workshops and conferences, data service, project support, research visits and doctoral program. IZA engages in (i) original and internationally competitive research in all fields of labor economics, (ii) development of policy concepts, and (iii) dissemination of research results and concepts to the interested public.

IZA Discussion Papers often represent preliminary work and are circulated to encourage discussion. Citation of such a paper should account for its provisional character. A revised version may be available directly from the author. 


\title{
ABSTRACT \\ Worth the Wait? The Effect of Early Term Birth on Maternal and Infant Health*
}

\begin{abstract}
Early term birth is defined as birth at 37 or 38 weeks gestation. While infants born early term are not considered premature, the medical literature suggests that they have an increased risk of serious adverse health outcomes compared to infants born at term (39 or 40 weeks). Despite these known harms, we document a rise in early term births in the United States from 1989 to the mid-2000's, followed by a decline in recent years. We posit that the recent decline in early term births has been driven by changes in medical practice advocated by American College of Obstetricians and Gynecologists recommendations and programs such as the March of Dimes' "Worth the Wait" campaign. We first show that this pattern cannot be attributed to changes in the demographic composition of mothers. We next exploit countylevel variation in the timing of these changes in medical practice and show that early term inductions lead to an increased risk of precipitous labor, lower birth weights and an increased risk of birth injury and required ventilation. Our results suggest that reductions in early term inductions can explain about one-third of the overall increase in birth weights for term births between 2010 and 2013.
\end{abstract}

JEL Classification: J13, I18

Keywords: infant health, maternal health, birth weight, induction of labor, early elective delivery

Corresponding author:

Kasey Buckles

Department of Economics

University of Notre Dame

436 Flanner Hall

Notre Dame, IN 46556

USA

E-mail: kbuckles@nd.edu

\footnotetext{
* We thank Madeline Organ for excellent research assistance. We are grateful to Amelia Bond, Cameron Kaplan, Brad Hershbein, and Emilia Simeonova and conference participations of the 2015 Association for Public Policy Analysis and Management in Miami, FL, the 2015 Southern Economic Association Meeting in New Orleans, LA, the 2016 Eastern Economic Association Meeting in Washington, D.C., and the 2016 American Society of Health Economists in Philadelphia for their comments. Any remaining errors are our own.
} 


\section{Introduction}

Despite technological advances and policy efforts aimed at improving infant health, average birth weights fell and the incidence of low birth weight rose in the United States during the 1990s and early 2000s (see Figure 1). However, beginning in the mid-2000s, these trends stabilized and even reversed course. These are welcome changes, given the large literature in economics and other disciplines documenting a relationship between low birth weight and diminished health and economic outcomes throughout the life course (Almond and Currie, 2010; Barker et al., 1993; Behrman and Rosenzweig, 2004; Black, Devereaux, Salvanes, 2007; and Oreopolous et al., 2008). Figure 1 shows that these patterns can be seen even for infants that are relatively healthy (born at 37 weeks gestation or more). Improvements in birth weight have been shown to have lasting benefits even at this margin; Royer (2009) shows positive educational returns to birth weight for babies born above $2500 \mathrm{~g}$.

These recent improvements in infant health have coincided with major policy efforts aimed at reducing the rate of early elective delivery (EED). Definitions of EED vary slightly, but typically a delivery is considered to be an EED if the mother or doctor elect to deliver the baby before 39 weeks gestation without a medical indication that the delivery is emergent. ${ }^{1}$ EED occur via Cesarean section (C-section) and/or induction of labor. While only births before 37 weeks gestation are classified as premature, those born early term (37 to 38 weeks gestation) are still more likely to experience diminished health outcomes than those born full term (39 to 40 weeks). Research shows that early term infants have increased risk of respiratory distress syndrome, ventilator use, 5-minute Apgar score less than 7, pneumonia, respiratory failure, neonatal intensive care unit admission, and even neonatal mortality than their full term counterparts (ACOG, 2013b; Tita et al., 2009; Clark et al., 2009; Madar, Richmond, and Hey, 1999; Shapiro-Mendoza CK et al., 2008). The risk of

\footnotetext{
${ }^{1}$ Main et al (2010) focuses on the elimination of "non-medically indicated (elective) deliveries before 39 weeks gestational age" and ACOG (2013b), discussed below, targets "non-medically indicated early term deliveries".
} 
respiratory distress, for example, may be 200 times higher at 37 weeks than at 39 weeks (Madar, Richmond, and Hey, 1999).

Given the evidence on the risks associated with early term births, the American College of Obstetricians and Gynecologists (ACOG) has recommended against inductions before 39 weeks unless medically necessary since at least 1979 (Main et. al., 2010). ${ }^{2}$ Despite this, the rate of early term births_-many of which are EEDs_-rose dramatically from 1989 to the mid-2000s. Perhaps in response to these trends, in 2007 ACOG produced the first of several reports that underscored the need to reduce EEDs when not medically indicated. This refocus of attention on EED in the mid2000s is described by Clark, Meyers, and Perlin (2012) who claim that over the period 2006 to 2011 there was a "...growing concern within both the obstetric and pediatric communities regarding the outcomes of infants who undergo elective early term delivery." In addition to ACOG, the push to reduce the rate of elective delivery before 39 weeks came from Medicaid and other insurers, and from advocacy groups like the March of Dimes which initiated a "Healthy Babies Are Worth the Wait" information campaign, starting with a pilot program in Kentucky in 2006-2009. This multipronged effort may have worked-since the mid-2000s the U.S. has experienced an increasing percentage of births occurring at 39 weeks and a concurrent decreasing percentage of births occurring at 37 and 38 weeks, which we show in Figure 2A. Furthermore, Figure $2 \mathrm{~B}$ shows a dramatic rise in the ratio of births at 39 weeks to those at 38 weeks beginning in 2006.

In this paper, we investigate how these policies aimed at reducing EEDs and promoting the goal of 39 weeks of gestation have affected infant and maternal health. In doing so, we hope to shed light on the causes of the recent improvements in infant health in order to help policy makers and practitioners identify the best steps forward for continuing that trend. Furthermore, most of

2 ACOG is a professional organization that provides recommendations on a variety of medical practices related to obstetrics and gynecology. The committee opinions and practice bulletins are written by a group who vets existing research and provides a recommendation to practitioners based on its interpretation of the research. More detail is provided in the background section. 
the evidence on the effects of gestation on health outcomes has focused on premature infants. While there is a large body of research establishing an increased risk of adverse outcomes for early term births compared to full term births, causal evidence of the effects of gestation on this margin is limited. $^{3}$ In 2005, around $28 \%$ of births in the United States were early term; policies that moved births from early term to full term could have had large aggregate health benefits even if the effect for any one birth was small.

We use birth certificate data to document dramatic changes in the rate of early term inductions (ETIs) between 1989 and 2013, where ETIs are our proxy for EEDs. First, we show that these changes are not driven by changes in the demographic characteristics of mothers. Next, we describe the major policy efforts and campaigns that occurred in the mid- to late-2000s that sought to curtail or eliminate EEDs. We discuss anecdotal evidence that these policies were effective and demonstrate this using the Kentucky pilot of the Worth the Wait program. Finally, we exploit geographic variation in the timing of the shift away from ETIs to evaluate the effect of ETIs on infant health. Using both county fixed effects models and an instrumental variables approach in which county-level ETI rates are used to instrument for the individual's likelihood of experiencing an ETI, we find that ETIs decrease birth weights and increase the probability of birth injuries, required ventilation, and precipitous labor. Our results suggest that reductions in early term inductions can explain about one-third of the overall increase in birth weights for term births between 2010 and 2013.

A few recent studies have considered the effects of EED policies on EED rates and on infant health. For example, research has shown that hospital-level policies (Clark et al., 2011) or changes in Medicaid reimbursement (Fowler et al., 2014) can effectively reduce early term births in

\footnotetext{
${ }^{3}$ Borra, Gonzalez, and Sevilla (2016) and Schulkind and Shapiro (2014) provide evidence that small changes in birth timing driven by tax incentives lead to worse infant health outcomes, even among full term births.
} 
targeted settings. In concurrent work, Byanova (2015) and Dahlen et al. (2016) each consider a 2011 change to Texas' Medicaid reimbursement policy. Dahlen et al. (2016) show that the change not only led to a $14 \%$ reduction in EEDs, but also increased birth weights. Byanova (2015), however, shows that while the targeted group experienced reductions in early elective deliveries, these were offset by the group not covered by Medicaid.

Our paper contributes to this nascent literature in two key ways. First, we conduct our analysis at the national level. This allows us to determine how much of the overall improvement in infant health in the United States since the mid-2000s can be attributed to changes in EED policy. Second, where previous research has examined the effects of individual policies or of policies that affected EEDs indirectly, we consider how the combined and targeted effort to change medical practice and patient beliefs regarding EED_from both public and private organizations at multiple levelsaffected maternal and infant health.

In the next section, we document the shifts toward and then away from early term births and ETIs between 1989 and 2013. In Section III, we describe policy efforts to reduce EEDs and present evidence of their effects on rates of early term births. We estimate the effect of ETIs on maternal and infant health in Section IV, and Section V concludes.

\section{Trends in Early Term Births}

We use Natality data from the National Center of Health Statistics over the period 1989 to 2013, with restricted use geo-coded data from 2005-2013. These data contain the universe of births in the United States and include a rich set of maternal and infant characteristics around the time of the birth. For example, we observe whether labor was induced, whether the infant was delivered by C-section, and demographic characteristics of the mother including her age, race, ethnicity, and marital status. For infants, we observe birth weight, a clinical estimate of gestation, parity, and 
gender. We also observe several risk factors and interventions for both the mother and infant. However, for many of these variables the definitions and incidence of non-reporting change over the period of our sample. ${ }^{4}$ We therefore limit our analysis to variables that can be consistently observed over time. These include indicators for precipitous labor, birth injury, and whether the infant required assisted ventilation.

We begin by constructing a county-level data set, where the individual-level birth certificate data are collapsed to cells by year of birth and county of occurrence. Because we are interested in early term inductions, we omit preterm births (those that occur before 37 weeks) from all data and results. Results using this data are weighted by cell size. Later, we will use data at the individual level; for these analyses we construct a $0.5 \%$ sample to lessen the computational burden. This sample includes 410,459 births. The summary statistics in Table 1 show very few differences between the $0.5 \%$ sample and the county level data (which can be interpreted as the population means, since they are weighted by cell size).

The intervention we are interested in is an early elective delivery (EED). Unfortunately, the birth certificate data do not identify EEDs, and so we calculate an alternative measure. We define an early term induction (ETI) as an induced delivery that occurs at 37 or 38 weeks gestation. In Figure 3, we show how this rate changed throughout the period. ${ }^{5}$ From 1989 to 2006, the ETI rate more than quadrupled, from $1.66 \%$ to $6.88 \%$ of births at 37 weeks gestation and above. However, we see a sharp decline in ETIs beginning in 2006; by 2013, the ETI rate is near 5\%. ${ }^{6}$

\footnotetext{
${ }^{4}$ In many cases these discrepancies are related to the 2003 birth certificate revision and the gradual transition to its use. ${ }^{5}$ We have also explored an alternative measure: ETI with no observable risk factor. These are ETIs where the birth record for the mother does not indicate diabetes, pregnancy-related hypertension, eclampsia, multiple birth, or a previous C-section. These factors are identified as medical indications for early-term deliveries by ACOG (ACOG 2013b). As Figure 3 shows, rates of ETI with no risk factor were lower than the overall ETI rate, but the two measures moved closely together between 1989 and 2013. However, because the risk factors are reported inconsistently across states and years, we have omitted those results here.

${ }^{6}$ Some EEDs are achieved by $\mathrm{C}$-section rather than by induction, which would cause us to underestimate the EED rate using our ETI measure. We do not include C-sections at 37 or 38 weeks of gestation in our measure because $\mathrm{C}$-section is a potential outcome of an induction (we discuss this more below). However, some inductions are medically necessary,
} 
We now investigate whether the trends shown in Figure 3 could be driven by changing demographic characteristics among mothers. Research by Dehejia and Lleras-Muney (2004) suggests this as a potential channel. The authors find that infant health improves when unemployment rates increase due to changing selection into motherhood. Unemployment rates in the United States more than doubled between 2007 and 2009 and remained high through 2013 —a time period that roughly coincides with the decline in ETIs seen in Figure 3. If selection into motherhood changed over this period, it could affect both ETI rates and infant health.

To test this, we follow an approach developed by Baicker, Buckles, and Chandra (2006). We begin by collapsing the data to cells by marital status, parity, child gender, race, state of residence, and single year of age. We then estimate the correlation between these demographic characteristics and ETIs in 2004 and 2005, using the following model:

$$
E T I_{j}=\alpha+\beta X_{j}+\varepsilon_{j}
$$

where $E T I_{j}$ is the early term induction rate for cell $j$, and $X_{j}$ is a vector of the above demographic characteristics for cell $j$. Estimating this model gives us the "return" to each characteristic, following 2004/2005 practice. Finally, we use the coefficient estimates for the $X_{j}$ variables to generate a predicted probability of intervention for later and earlier years. This allows us to compare observed rates to predicted rates to show how the intervention rate would have evolved if obstetric practices had been constant at 2004-2005 levels.

The results of this exercise are shown in Figure 4. The actual ETI rate is the same as in Figure 3. The solid line shows the predicted ETI rate for each year, given the demographic composition of mothers in that year. Had 2004/2005 practice been in place in every year, the ETI rate would actually have declined gradually over the period. There would have been no rapid

including for reasons that are unobservable in the data. This would cause us to overstate the rate of EEDs. While the rate of EEDs nationwide is unknown, Clark et al. (2010) collected data from 27 hospitals with more detailed information on EEDs, and found that in 2007, the EED rate was 9.7\%. For comparison, our 2007 ETI rate is $6.7 \%$. 
increase before 2006, and little to no decline afterward. We therefore conclude that changing demographic characteristics of mothers cannot explain the dramatic changes in the ETI rate over this period. In the remainder of the paper, we consider an alternative explanation for the recent declines in ETI rates and for improvements in infant health: policy efforts to reduce ETI rates using both supply- and demand-side interventions. We describe several of these efforts in the next section.

\section{Policy Efforts to Reduce Early Elective Deliveries}

Between 2000 and 2013, several organizations worked to increase the visibility of 39 weeks gestation as an important pregnancy goal. These include ACOG, the March of Dimes, state organizations, and the Department of Health and Human Services, who coordinated campaigns and successfully advocated for changes in government policy. We now describe these efforts in more detail.

\section{ACOG Recommendations}

The American College of Obstetricians and Gynecologists regularly publishes practice bulletins and committee opinions based on medical research. These publications communicate advances in research and recommend changes in practice to providers making medical decisions on behalf of patients. As new research changes the consensus opinion, new reports supersede old reports and presumably medical practice evolves. While there is not, to our knowledge, a nationally representative survey exploring whether doctors respond to the information contained in these reports, a small area survey conducted in Wisconsin suggests that a substantial fraction (31\%) required ACOG to recommend it before they would adjust practice (Al-Niaimi et al., 2008). This 
suggests that ACOG recommendations could meaningfully change practice, though it is not the only channel through which this happens.

Appendix Table 1 provides a list of the ACOG Committee Opinions and Recommendations related to elective inductions, C-sections, and early term deliveries since 1999. As we discuss in the introduction and show in Figure 2, over the period 1989 to 2005, the rate of early term deliveries grew continuously while the rate of births at 40 and 41 weeks dropped. These trends occurred even though ACOG has recommended against elective delivery before 39 weeks since 1979, and despite the growing body of medical research documenting risks associated with early term births and with elective delivery. ${ }^{7}$ Around 2006-2007, these trends shifted with 39 weeks representing a growing proportion of births. A closer read of the 2007 and 2009 ACOG recommendations reveals that while delivery before 39 weeks was discouraged through 2007, there were exceptions. For example, although C-section on maternal request before 39 weeks was discouraged, the 2007 recommendation suggested it was acceptable as long as lung maturity was documented (ACOG, 2007). Only two years later, ACOG's reports began to make fewer exceptions for delivery before 39 weeks. Practice Bulletin Number 107 (ACOG, 2009) recommended that delivery should not be induced before 39 weeks unless medically indicated and also provided a detailed list of ways to confirm gestational age prior to delivery to ensure delivery at 39 weeks or greater. ${ }^{8}$ Furthermore, unlike the 2007 report regarding C-sections, this report explicitly ruled out elective inductions before 39 weeks even if evidence of lung maturity is present. In 2013, two new committee opinions recommended against maternal request for C-section, especially for delivery before 39 weeks gestation (No. 559), recommended no delivery before 39 weeks gestation unless medically indicated

\footnotetext{
${ }^{7}$ Main et. al, 2010; ACOG 2013b.

8 According to ACOG No. 107 (2009), term gestation should be confirmed with ultrasound measurement at less than 20 weeks; fetal tones present for 30 weeks; or 36 weeks since a positive pregnancy test. This list has been present in ACOG recommendations since at least 1999. The earlier recommendations, however, do not focus on 39 weeks gestation within the text, suggesting that this was not a primary focus at that time. (ACOG No. 10, 1999).
} 
(No. 561), and provided evidence on negative health consequences for infants born near term (No.

561). Taken together, these reports suggest that we might expect to see declines in EED (and our proxy, ETI) in 2007, but to a larger degree in 2009, and again in 2013 in response to the changing ACOG recommendations.

\section{Healthy Babies are Worth the Wait}

The March of Dimes is a non-profit organization with a mission "to improve the health of babies by preventing birth defects, premature birth, and infant mortality." ${ }^{9}$ In 2006, the March of Dimes began planning a pilot program in Kentucky, named Healthy Babies Are Worth the Wait (HBWW), which ran there from 2007-2009. An essential goal of HBWW is to reduce the demand for elective births before 39 weeks. In 2010, California collaborated with March of Dimes to develop a HBWW toolkit, which provides materials for organizations interested in implementing HBWW. ${ }^{10}$ Within this framework, providers as well as patients are given information via a public awareness campaign regarding the harms of non-medically indicated births before 39 weeks (the ACOG guidelines). For doctors and nurses this may include workshop education and for patients this may include videos in the waiting room, social media, or information pamphlets. ${ }^{11}$ The second part of the toolkit provides strategies to enforce the guidelines with medical leadership, including tracking progress using quantitative measures. One quality measure suggested in the toolkit is the

\footnotetext{
${ }^{9}$ http://www.marchofdimes.org/ accessed 10/29/15.

10 The toolkit is "Elimination of Non-medically Indicated (Elective) Deliveries Before 39 Weeks Gestational Age" and is referenced as Main et. al., 2010 in this document.

${ }^{11}$ The HBWW focus on patients was potentially important, as there is survey evidence that the perception by patients as to what constituted a full term birth has not always concurred with best medical practice. In 2008, a major insurance company asked individuals "What is the earliest point in pregnancy that it is safe to deliver the baby, should there be no other medical complications requiring early delivery?” Over 50\% answered between 34 to 36 weeks, and a substantial minority (40\% of respondents) answered 37 to 38 weeks (Goldenberg et al, 2009).
} 
rate of early term births without medical indication before 39 weeks. ${ }^{12}$ It is the combination of education plus enforcement of the guidelines that appear to lead to meaningful changes in early elective deliveries (Main et. al., 2010). The toolkit materials are part of the basis for the Strong Start program, which began in 2012 and which we discuss below (Main et. al, 2010). ${ }^{13}$

Kentucky was identified as a good place to run a HBWW pilot program targeting early term birth because it had one of the highest EED rates in the country, a sufficient number of births for statistical power, and a desirable population mix. ${ }^{14}$ The planning for the program began in 2006 and it was implemented from 2007 to 2009 . The state was broken into 3 study areas and within areas the intervention was performed in one hospital (the treatment group) but not the other (the control group). In principle, we can use our birth certificate data to look for the effects of this pilot program. However, two of three hospitals were in counties too small to be identified in our birth certificate data (Trover Clinic in Lyon County and King's Daughters in Boyd County). The third hospital was the University of Kentucky Medical Center in Fayette County; this hospital accounted for about $31 \%$ of hospital beds in Fayette County in $2013 .{ }^{15}$

In Figure 5 we show how the ratio of births in week 39 to those in week 38 evolved in Fayette County between 1989 and 2013. Fayette County is the second largest county in Kentucky; we also show this ratio for the largest (Jefferson County, which also housed the control hospital for

\footnotetext{
12 The National Quality Forum, the Joint Commission, and LeapfrogGroup each include this quality measure and it is used to evaluate hospital performance. These are newer measures, however. For example, the Joint Commission only developed their measure in 2010 (http://www.marchofdimes.org/professionals/less-than-39-weeks-toolkit.aspx). Clark et al (2011) discuss these measures in more detail.

13 https://wayback.archive-

it.org/3926/20150121155550/http://www.hhs.gov/news/press/2012pres/02/20120208a.html;

http://www.marchofdimes.org/news/march-of-dimes-healthy-babies-are-worth-the-wait-elevated-to-national-healthagenda.aspx

http://www.huffingtonpost.com/2012/02/08/march-of-dimes-healthy-ba_n_1263820.html accessed 10/29/15

14 The information in this paragraph is drawn heavily from two sources: a presentation "Community-Based Prematurity Prevention: The Kentucky Experience” presented at the HRSA Regional Infant Mortality Summit, January 12-13, 2012; and McCabe (2015).

${ }^{15}$ Hospital bed counts from the Kentucky Hospital Association, www.kyha.com. Our count excludes speciality hospitals (veterans, mental, behavioral).
} 
the UK Medical Center) and for births in the rest of the state. This figure shows that the 39/38 week ratio in Fayette County moved closely with the ratio in the rest of the state, through 2006. Beginning in 2007, however, Fayette County had a higher ratio-meaning more births at 39 weeks relative to those at 38-and it maintained this advantage until 2012. Thus, it appears that the HBWW pilot did effectively reduce early term births. However, the figure shows that the "control" counties also experienced an increase in this ratio after 2007, and eventually caught up to Fayette County. Although the pilot program was designed to minimize spillovers (the control hospitals had to be at least 70 miles from the treatment hospitals and also had to be in a different county), an evaluation of the program by the March of Dimes suggests that "...there may have been positive program effect of HBWW across Kentucky" (McCabe, 2015 p. 41). This illustrates some of the empirical challenges in using variation in individual policies to do a national level analysis-an issue we return to when we present our estimation strategy below.

\section{State and Other Initiatives}

After the Kentucky pilot, many states and other organizations begin their own targeted efforts to decrease early elective deliveries such as campaigns like the "Go the Full 40 Campaign" by the Association of Women's Health, Obstetric and Neonatal Nurses. These programs encouraged providers to decrease the rate of EEDs and aided in educating the general public regarding the potential harms of births before 39 weeks. ${ }^{16}$ The state initiatives often listed reducing EED rates as a primary objective. ${ }^{17}$ Here we offer details from Ohio and Georgia to provide some examples of how medical practice related to early term births changed at the state level due to these local initiatives.

\footnotetext{
${ }^{16}$ A description of several state initiatives are available in this transcript: http://innovation.cms.gov/Files/transcripts/StrongStart_ElectiveDelivery_Trscrpt.pdf. Information on the "Go the Full 40 Campaign" is available in the following press release: https://www.awhonn.org/awhonn/content.do?name=07_PressRoom/7B7_Jan20_Full40.htm.

${ }_{17}$ These state initiatives were often coordinated by a state "Prenatal Quality Collaborative." As of 2016, we were able to find evidence of a PQC in 39 of the 50 states.
} 
Both Ohio and Georgia formed centralized committees comprised of stakeholders representing the perspectives of providers (hospitals, clinicians), policy makers (public health officials), and other parties (insurance companies, March of Dimes). In each state, these committees use a data-intensive approach to help inform medical practice related to infant health and incorporated educational components and hospital "rules" in the initiatives they developed.

Ohio’s Perinatal Quality Collaborative (OPQC) was established in 2007 and was tasked with finding ways to decrease infant mortality and improve infant health outcomes (OPQC Collaborative Writing Committee, 2010). ${ }^{18}$ The committee recognized that the increasing number of early term infants admitted to the NICU as a particular concern and targeted a $60 \%$ reduction in the scheduled EED rate within one year beginning in September, 2008 (OPQC Collaborative Writing Committee, 2010). The OPQC strategy to reduce EED incorporated a number of elements from the medical literature and ACOG recommendations and contained an educational component for providers and mothers. Using data representing 47\% of Ohio's births, the OPQC found that the rate of scheduled early term births declined from $25 \%$ to less than $5 \%$ and concluded that applying ACOG criteria for determining gestational age was the main reason for the decline.

Georgia instituted a similar task force in early 2012. ${ }^{19}$ Yet, before the Georgia consortium was established, the state's EED was already falling; it decreased from 65\% in 2009 to 35\% in 2010 (CMS, 2012). This suggests that some doctors and hospitals may have already been responding to the accumulating scientific evidence that elective birth before 39 weeks is harmful to infant health. Even so, the Centers for Medicare and Medicaid (CMS) contacted the state and asked them to target a reduction in EED as part of their $40 / 20$ by 13 program. ${ }^{20}$ In response, Georgia organized a State

\footnotetext{
18 The information regarding Ohio is drawn from The Ohio Perinatal Quality Collaborative Writing Committee (2010). This paper was presented in February 2010 at the Annual Meeting of the Society for Maternal-Fetal Medicine. According to the article, it was published quickly "for the benefit of the scientific community" (p. 243.e1).

${ }^{19}$ The information in this paragraph is drawn heavily from CMS, 2012, p. 17-21.

20 The $40 / 20$ by 13 program is a target of 40\% reduction in harm and 20\% reduction in readmissions by 2013 .
} 
Action Group. This group utilized some of the framework provided by the March of Dimes toolkit as well as procedures and policies that had worked well at hospitals in Georgia to put together an effective strategy (CMS, 2012). In particular, their educational component paid substantial attention to "hard stop" policies, which do not allow for a mother to be scheduled to delivery before 39 weeks without a medical indication. "Hard stop" policies appear to be the most effective policy for reducing EEDs, likely because they allow the hospital to enforce the ACOG recommendations at the system level rather than doctor-by-doctor (Berrien et al., 2014). The plan was implemented in March of 2012. Of the 83 birthing hospitals in Georgia, the State Action Group was able to obtain data from 58. Nineteen of these were already at a 0\% EED rate in 2012, but roughly a third had EED rates higher than 10\%. By August of 2012, the state average EED had fallen below 4\%.

\section{Strong Start and Medicaid}

Most recently, in February of 2012, the Department of Health and Human Services launched the "Strong Start" initiative. ${ }^{21}$ This program offered $\$ 40$ million in grants targeted to improve the prenatal care and health outcomes of infants, including an explicit target of reducing early term elective deliveries. These grants are distributed by the Center for Medicare and Medicaid Innovation to providers serving women covered by Medicaid. The first grant applications were due in August of 2012, and in November of 2012 the Center for Medicare and Medicaid Innovation hosted a webinar which provided information regarding earlier initiatives such as the HBWW and other state programs, and encouraged entities to apply for these grants to implement similar changes in their organizations (CMS, 2012). ${ }^{22}$

\footnotetext{
21 This paragraph draws on the press release announcing the Strong Start program: https://wayback.archiveit.org/3926/20150121155550/http://www.hhs.gov/news/press/2012pres/02/20120208a.html

22 http://www.federalgrants.com/Strong-Start-for-Mothers-and-Newborns-33628.html
} 
Grants distributed by the Center for Medicare and Medicaid Innovation have the potential to affect a large number of births in the United States. Medicaid paid for just over 44 percent of births in the United States in 2010, ${ }^{23}$ and Fowler et al. (2014) found that nearly 9 percent of Medicaid births in 2010-2012 were EED. In addition to the Strong Start initiative, given the higher health care costs of sicker newborns, Medicaid, like other insurers, has the incentive to improve infant health where possible in order to curtail costs. Since infants born early term are more likely to be admitted to the NICU, Medicaid focused its attention toward reducing early term births in the late 2000s. Since Medicaid is administered at the state level, states were individually making changes regarding EED starting in the late-2000s as we show in Appendix Table 2. State Medicaid programs implemented several different policies including incentives to reduce EED, refusing to pay for EED, collaborative strategies, and "hard stop" policies.

\section{The Effects of ETI on Infant and Maternal Health}

Taken together, the various policy efforts described in the previous section are expected to begin shifting births to 39 weeks around 2006, when the earliest pilot program starts. Births are expected to continue to shift to 39 weeks from that point on as medical evidence and policy recommendations continue to underscore weeks 39 and greater as more desirable gestational targets.

The goal of the empirical work in this section is to use these changes in EED policy to estimate the effects of EEDs on maternal and infant health. However, the fact that there were so many different policy changes at levels that do not always align with counties or states presents a challenge for our estimation. This is illustrated by the Kentucky case. First, while Fayette County received the HBWW intervention, Figure 5 shows that even in the "control" parts of state, term births increased relative to early term births from 2007-2013, so that eventually there was no

${ }^{23} \mathrm{http}: / / \mathrm{kff}$. org/medicaid/state-indicator/births-financed-by-medicaid/ 
difference in the ratio. This is likely the result of pressures to change medical practice during this time period from sources other than HBWW, and/or a potential "contagion" effect from the HBWW pilot. Second, the HBWW pilot was at the hospital level-just like many other efforts around the country. It would be infeasible to collect national-level information on hospital policy (and hospitals may not have detailed records of the timing and specifics of their policies) and then map these changes to county-level birth certificate data.

Rather than attempting to identify all the changes in policy and practice that would have affected the probability of an ETI (our proxy for EEDs) we instead exploit county-level variation in the timing of shifts in ETI rates. We document this geographic variation at the state level in Figure 6. For example, Delaware had a relatively high rate of ETI prior to 2001, but its rate began to decline at that time-earlier than the national average. Meanwhile, Arkansas did not see its rate begin to decline until 2008. Changing to county-level data, in Figure 7 we show how the distribution of ETI rates evolved over time, from 1992 to 2013. For each year, county-level ETI rates range from near zero to fifteen percent or more. When ETI rates were at their peak in 2006 at near seven percent, five of the 433 counties in the data had rates below 1\%, and seven counties had rates above 19\%. The standard deviation was 3.78 .

We estimate the effects of changes in EED policy on infant health using a differences-indifferences approach, exploiting this county-level variation in the timing of changes in our two measures of EED: ETI rates and the 39/38 week ratio. The estimated model is as follows:

$$
Y_{c t}=\alpha+\delta Z_{c t}+\beta X_{c t}+T_{t}+\gamma_{c}+\text { trend }_{c}+\varepsilon_{c t}
$$

where $Y_{c t}$ is a measure of infant or maternal health in the county $\mathrm{c}$ and year $\mathrm{t}$. These measures include the rate of $\mathrm{C}$-section and precipitous labor, average birth weight in grams, and the incidence 
of low birth weight, birth injury, or required ventilation of the infant; we discuss these measures in more detail below. $Z_{c t}$ is either the ETI rate or the standardized 39/38 weeks gestation ratio. $\mathrm{X}_{\mathrm{ct}}$ includes county-level averages for the demographic characteristics included in Table 1, and $\mathrm{T}_{\mathrm{t}}$ indicates year fixed effects. Standard errors are clustered at the county level.

Our differences-in-differences strategy rests on two assumptions. First, we assume that the timing of the county-level changes in ETI rates did not coincide with other changes that might have affected infant health. For example, counties taking action to reduce EEDs may have also been working to increase access to prenatal care at the same time. To address this concern, the matrix $\mathrm{X}_{\mathrm{ct}}$ also includes the fraction of births less than 33 weeks and the 36/35, 35/34, and 34/33 week ratios as controls. These measures of infant health for infants born preterm (who are therefore not in our sample) serve as proxies for county-level efforts to improve infant health, since these efforts would likely have affected preterm births as well. The second assumption is that the timing of the countylevel ETI changes is plausibly exogenous. That is, the variation is driven by differential timing in the implementation of the above policies, and not by (for example) responses to changes in the EED rate or by unobserved differences in counties. Here, we include not only county-level fixed effects $\left(\gamma_{c}\right)$, but also either linear or quadratic county-specific time trends $\left(\right.$ trend $\left._{c}\right)$.

Our maternal health outcomes are the C-section rate and the rate of precipitous labor. We include C-sections as an outcome because previous research has linked EED with an increased need for C-section (Seyb et al. 1999). However, EED can be achieved either with an induction or with a scheduled C-section. We therefore caution that changes in $\mathrm{C}$-section rates in response to countylevel changes in the ETI rate could be due to a direct effect of EED policy on C-sections, in addition to any effect of inductions on C-sections. Again, our interpretation of the results is that our ETI measure is a proxy for EED rates, which could affect C-section rates through either channel. 
Our second outcome measure is the county-level precipitous labor rate. In the birth certificate data, births are labeled as "precipitous" if fewer than three hours elapse between the first contraction and the birth of the infant. While on average, induced births take longer when compared with spontaneous labor (Harper et al. 2012), some methods of induction have been shown to cause hyperstimulation of the uterus and fast labors (Hofmeyr 2003). For example, Heimstad et al. (2007) found that in a randomized controlled trial that compared term women whose births were induced to those receiving "expectant management" found that the rate of precipitous labor was 2.75 times higher in the induced group. Precipitous labor has been shown to be linked to adverse health outcomes for the mother, including cervical and perineal tears, postpartum hemorrhage, retained placenta, "the need for revision of uterine cavity and packed-cell transfusions," and prolonged hospitalization (Sheiner, Levy, and Mazor 2004).

The measures of infant health are birth weight in grams, and indicators for low birth weight ( $<2500$ grams), birth injury, and ventilation of the infant. The birth weight measures are included given the well-known relationship between gestation and birth weight, and the association between birth weight and later outcomes (Almond and Currie, 2010). Birth injury is included because of its known association with inductions (Dublin et al. 2000), and the risk of assisted ventilation is much higher for early term births than for full term births (Madar, Richmond, and Hey, 1999).

The results from estimating equation (2) are in Table 2. We find no statistically significant association between either measure of EED and the C-section rate at the county level. County-level ETI rates are associated with increases in the risk of precipitous labor. Using the coefficient from the linear specification, one standard-deviation increase in the ETI rate is associated with a 0.14 percentage point increase in precipitous labor rates, or a $6.9 \%$ increase relative to the mean. Turning to the results for infant health outcomes in Table 2, we do find that high county-level ETI rates are associated with a decrease in average birth weight. Increasing the ETI rate in a county by one 
standard deviation is associated with a decrease of 8.0 to 9.6 grams in average term birth weights, and with an increase in the incidence of low birth weight of about 0.05 percentage points $(1.7 \%$ relative to the mean). Results are similar using the 39- to 38-week ratio as our measure of EED. ${ }^{24}$ We also see that higher ETI rates are associated with an increased risk of birth injury and ventilation, though the results are only statistically significant in the quadratic specification.

The results in Table 2 show how changes in the aggregate level of ETI affect aggregate measures of maternal and infant health. We can also exploit the within-county variation in the ETI rate over time to investigate how having an ETI affects an individual mother and baby. As discussed above, there is a large medical literature documenting an association between EED and adverse health outcomes, but these studies are subject to concerns about endogenous selection into EEDs. To address this issue, we employ an instrumental variables strategy, in which the ETI rate and 39/38 week ratio in the county of delivery are used as instruments for whether or not the mother had an ETI. The "natural experiment" we have in mind is one in which some mothers in the same county find themselves more or less likely to have an ETI, depending on the policy environment in the year of their delivery.

For our identification strategy to be valid, we need 1) that the county measures do not affect the health outcomes for the individual mother or child, other than by affecting her likelihood of having an ETI, and 2) that the county ETI rate and 39/38 ratio are correlated with the mother's probability of having an ETI. While we cannot test the first, we argue that any within-county variation in ETI rates and the 39/38 ratio is likely to be driven by the policy changes discussed in Section III, and should therefore not be correlated with any one mother's unobservable characteristics. Effectively, the assumptions we are making here are the same as those needed for the difference-in-difference model above, and so we continue to use county-specific time trends and

${ }^{24}$ With an increase of the 39/38 week measure, we expect opposite signed estimates compared to an increase of the ETI measure. 
controls for measures of the health of pre-term infants in the county. The second condition is testable, and we document a strong correlation between within-county ETI rates and the mother's probability of an ETI. The F-statistics for the exogenous variables far exceed 10 for all samples.

Results from this exercise are in Table 3. The sample is the $0.5 \%$ population sample summarized in Table 1. We show both the OLS for the individual-level regressions, and the twostaged least squares results. Beginning with the maternal health outcomes, we see that at the individual level, the OLS results show a negative association between ETI and C-section birth. This may reflect a positive selection into ETI—physicians may only perform them when they believe the birth to be low-risk. For the IV results, the coefficient is not statistically different from zero. For precipitous labor, OLS estimates show a negative relationship between ETI and precipitous labor. However, the IV results show a positive effect of ETIs, consistent with the differences-indifferences results strategy above. The magnitude of the coefficient is large, showing that an ETI increases the rate of precipitous labor by 3.5 to 4.6 times, relative to the mean of 0.0202 . Importantly, this result is comparable to those obtained in a randomized trial, which showed that induction increased the rate of precipitous labor 2.75 times (Heimstad et al. 2007). ${ }^{25}$

Turning to infant health outcomes, we confirm that ETI decreases birth weights and increases the incidence of low birth weight $(<2500$ grams), though results for the latter are not statistically significant. For an individual, the IV results show that having an ETI decreases birth weight by 218 to 251 grams (6.4-7.4\% of the mean). To put this magnitude in context, our IV estimates give the local average treatment effect (LATE) — that is, the average effect of an ETI for women whose ETI status is affected by local practice. If these women see their gestation increased

\footnotetext{
25 The Heimstad study sample included only post-term births; the effect of induction on precipitous labor may be different for early term births.
} 
by one to two weeks, this could easily generate an increase in birth weight of this magnitude, given that infants gain 230 grams per week on average during the last few weeks of pregnancy. ${ }^{26}$

Finally, our IV results show that ETI increases the risk of birth injury about eight-fold and the risk of ventilation about four-fold. Again, these magnitudes are large, but plausible given the LATE interpretation. With ventilation in particular, Madar, Richmond, and Hey (1999) show that the risk of respiratory distress is 200 times higher at 37 weeks than at 39 weeks. Local changes in EED policy that move women from early term to full term births could therefore have large effects on these outcomes.

\section{Discussion and Conclusion}

We document a dramatic shift in the United States from term (39 to 40 weeks) to early term (37 to 38 weeks) births between 1989 and the mid-2000s. This shift to early term births appears to move in lock step with a rise in early term inductions (ETIs) as well as with a decline in infant health at birth (as measured by birth weights). We show that these trends reversed course in the mid2000s, when the data show an increasing proportion of births occurring at 39 weeks and a commensurate improvement in infant health. These shifts in the timing of term births and the rates of ETIs cannot be attributed to changing demographics.

Next we discuss the history of changes to policy and practice that emphasized the risks associated with early elective deliveries and early term births. These include the March of Dimes' "Worth the Wait" campaign and the Department of Health and Human Services" "Strong Start" program, as well as American College of Obstetricians and Gynecologists recommendations and individual state initiatives. These policies coincided with the decline in ETIs, though the timing of

${ }^{26}$ http://www.mayoclinic.org/healthy-lifestyle/pregnancy-week-by-week/in-depth/fetal-development/art20045997?pg=2, accessed July 14, 2016. 
the decline varies considerably across states and counties. We exploit the variation in the timing of the decline in ETIs within and across counties to investigate the effects of this shift on infant and maternal health. While infants born at 37 to 38 weeks are not considered premature, we show that ETIs lead to many of the same negative outcomes as being born preterm, including lower birth weights and increased probability of precipitous labor, birth injury, and required ventilation.

Our estimates can be used to measure the benefits of the multi-pronged effort to reduce ETIs for both individuals and for society. First, at the individual level, our IV estimates identify the improvements in maternal and infant health for the marginal ETI that is prevented by local policy efforts. We estimate that preventing this marginal ETI increases birth weight by 218 to $251 \mathrm{~g}$. In addition to the short-term benefits from this improvement in infant health, there are likely long-term benefits for human capital development. Royer (2009) shows that a $200 \mathrm{~g}$ increase in birth weights yields 0.04 additional years of education; Black, Devereaux, and Salvanes (2007) predict that a 200g increase in birth weight would increase male earnings by about $2 \%$, height by half a centimeter, and IQ by $1 / 25^{\text {th }}$ of a standard deviation. ${ }^{27}$

These improvements in initial health and in long-term human capital have spillovers for society as well, translating into greater tax revenue and possibly lower public assistance dependence going forward. In aggregate, these effects could be large because the number of affected births is large_ETI rates fell nearly two percentage points since their peak in 2006, so that there are now over 70,000 fewer ETI deliveries per year. Gains for society also come in the form of reduced health care costs. Our fixed effects estimates show that reducing a county's ETI rate decreases the

27 Royer (2009) concludes that "The positive effect of birth weight on education is largest for births exceeding 2,500 grams, a range where outcomes are often assumed to be unaffected by birth weight. This is a new and important finding suggesting that returns to increases in birth weight may be reaped from "normal-weight" births." 
rate of low birth weight, birth injury, assisted ventilation, and precipitous labor —all of which often involve extended hospital stays or other costly medical interventions. ${ }^{28}$

Finally, we return to our initial question: did the shift away from ETIs contribute to recent improvements in infant health among births at 37 weeks gestation or more in the United States? Our estimates suggest that it did. Average birth weight among these births reached a low in 2010 before climbing in 2013. Over those three years, average birth weights rose by 7.6 grams. At the same time, the ETI rate decreased by 0.84 percentage points ( $0.29 \mathrm{SD})$. Using our coefficient estimates from Table 2, this change in the ETI rate would have increased average birth weights by 2.31-2.78 grams, or about one-third of the total increase. In summary, our study shows that collective change in medical practice, while admittedly difficult to measure, can have substantial effects on health outcomes.

\footnotetext{
${ }^{28}$ In some cases these complications lead to neonatal intensive care unit (NICU) stays. NICU stays account for 75 percent of the costs to care for newborns, with daily NICU costs estimated at $\$ 3,000$ (Kornhauser and Schneiderman, 2010). Although we cannot directly study NICU admission over the period we consider due to inconsistent measures of the variable, other research has shown that EEDs have a higher risk of a NICU stay; Clark et al (2009) estimate that EED leads to a NICU admission for $8 \%$ of infants born at 38 weeks gestation but only $4.6 \%$ for gestations of 39 weeks or more.
} 


\section{References}

Al-Niaimi, A., Chauhan, S. P., Gupta, L. M., \& Bailet, J. W. (2008). Factors influencing the evolving practice of obstetricians in eastern Wisconsin: a survey. American Journal of Perinatology, 25(06), 321-324.

Almond, D. \& Currie, J.. (2010). Human capital development before age five.” NBER Working Paper No. 15827.

American College of Obstetricians and Gynecologists. (2013a). "Caesarean delivery on maternal request," ACOG Committee Opinion No. 559.

American College of Obstetricians and Gynecologists. (2013b). "Nonmedically-indicated early term deliveries," ACOG Committee Opinion 561: 1-5. http://www.acog.org/Resources-AndPublications/Committee-Opinions/Committee-on-Obstetric-Practice/NonmedicallyIndicated-Early term-Deliveries

American College of Obstetricians and Gynecologists. (2007). "Caesarean delivery on maternal request," ACOG Committee Opinion No. 394. Obstetrics and Gynecology, 110, 1501-1504.

American College of Obstetricians and Gynecologists. (1999). "Induction of Labor". ACOG Practice Bulletin No. 10.

American College of Obstetricians and Gynecologists. (2009). "Induction of Labor". ACOG Practice Bulletin No. 107.

Baicker, K., Buckles, K. S., \& Chandra, A. (2006). Geographic variation in the appropriate use of cesarean delivery. Health Affairs, 25(5), w355-w367.

Barker, D. J., Godfrey, K. M., Gluckman, P. D., Harding, J. E., Owens, J. A., \& Robinson, J. S. (1993). Fetal nutrition and cardiovascular disease in adult life. The Lancet, 341(8850), 938-941.

Behrman, J. R., \& Rosenzweig, M. R. (2004). Returns to birthweight. Review of Economics and Statistics, 86(2), 586-601. 
Berrien, K., Devente, J., French, A., Cochran, K. M., McCaffrey, M., Horton, B. J., \& Chescheir, N. (2014). The Perinatal Quality Collaborative of North Carolina's 39 Weeks Project: A quality improvement program to decrease elective deliveries before 39 weeks of gestation. North Carolina Medical Journal, 75(3), 169-176.

Black, S. E., Devereux, P. J., \& Salvanes, K. G. (2007). From the cradle to the labor market? The effect of birth weight on adult Outcomes" Quarterly Journal of Economics, 122(1).

Borra, C., González, L., \& Sevilla, A. (2016). Birth timing and neonatal health. The American Economic Review, 106(5), 329-332.

Byanova, D. (2015). "Is it worth the wait? Early elective deliveries, procedure use \& neonatal health" unpublished manuscript. https://drive.google.com/file/d/0B1YDVquE_3rhdkJhNzFPQ1hSYm8/view?pref=2\&pli $=1$, accessed 7-15-16.

Center for Medicare and Medicaid Services. (2012). "Strong Start for Mothers \& Newborns Reducing Early Elective Deliveries Webinar Final Transcript" Prepared by: Healthcare Management Solutions, LLC Webinar Date: November 28, 2012. http://innovation.cms.gov/Files/transcripts/StrongStart_ElectiveDelivery_Trscrpt.pdf accessed 9-30-15.

Clark, S. L., Miller, D. D., Belfort, M. A., Dildy, G. A., Frye, D. K., \& Meyers, J. A. (2009). Neonatal and maternal outcomes associated with elective term delivery. American Journal of Obstetrics and Gynecology, 200(2), 156-e1.

Clark, S. L., Frye, D. R., Meyers, J. A., Belfort, M. A., Dildy, G. A., Kofford, S., ... \& Perlin, J. A. (2010). Reduction in elective delivery at $<39$ weeks of gestation: comparative effectiveness of 3 approaches to change and the impact on neonatal intensive care admission and stillbirth. American Journal of Obstetrics and Gynecology, 203(5), 449-e1. 
Clark, S. L., Meyers, J. A., Frye, D. K., \& Perlin, J. A. (2011). Patient safety in obstetrics-the Hospital Corporation of America experience. American Journal of Obstetrics and Gynecology, 204(4), 283-287.

Clark, S. L., Meyers, J. A., \& Perlin, J. B. (2012). Oversight of elective early term deliveries: avoiding unintended consequences. American Journal of Obstetrics and Gynecology, 206(5), 387-389.

Dahlen H, McCullough M, Fertig AR, Dowd B, Riley W. (2016). The effect of medicaid payment reform on early elective deliveries. Unpublished manuscript.

Dehejia, R., \& Muney, A. L. (2004). Booms, busts, and babies' health. Quarterly Journal of Economics, (3), 1091-1130.

Dublin, S., Lydon-Rochelle, M., Kaplan, R. C., Watts, D. H., \& Critchlow, C. W. (2000). Maternal and neonatal outcomes after induction of labor without an identified indication. American Journal of Obstetrics and Gynecology, 183(4), 986-994.

Fowler, T. T., Schiff, J., Applegate, M. S., Griffith, K., \& Fairbrother, G. L. (2014). Early elective deliveries accounted for nearly 9 percent of births paid for by Medicaid. Health Affairs, 33(12), 2170-2178.

Goldenberg, R. L., McClure, E. M., Bhattacharya, A., Groat, T. D., \& Stahl, P. J. (2009). Women’s perceptions regarding the safety of births at various gestational ages. Obstetrics \& Gynecology, 114(6), 1254-1258.

Harper, L. M., Caughey, A. B., Odibo, A. O., Roehl, K. A., Zhao, Q., \& Cahill, A. G. (2012). Normal progress of induced labor. Obstetrics \& Gynecology, 119(6), 1113-1118.

Heimstad, R., Skogvoll, E., Mattsson, L. Å., Johansen, O. J., Eik-Nes, S. H., \& Salvesen, K. Å. (2007). Induction of labor or serial antenatal fetal monitoring in postterm pregnancy: a randomized controlled trial. Obstetrics \& Gynecology, 109(3), 609-617. 
Hofmeyr, G. J. (2003). Induction of labour with an unfavourable cervix. Best Practice \& Research Clinical Obstetrics \& Gynaecology, 17(5), 777-794.

Kornhauser, M., \& Schneiderman, R. (2010). How plans can improve outcomes and cut costs for preterm infant care. Managed Care (Langhorne, Pa.), 19(1), 28.

Madar, J., Richmond, S., \& Hey, E. (1999). Surfactant-deficient respiratory distress after elective delivery at 'term'. Acta Paediatrica, 88(11), 1244-1248.

Main E, Oshiro B, Chagolla B, Bingham D, Dang-Kilduff L, and Kowalewski L. (2010). Elimination of Non-medically Indicated (Elective) Deliveries Before 39 Weeks Gestational Age. (California Maternal Quality Care Collaborative Toolkit to Transform Maternity Care). Developed under contract \#08-85012 with the California Department of Public Health; Maternal, Child and Adolescent Health Division; First edition published by March of Dimes. McCabe, E. R. (2015). Healthy Babies are Worth the Wait: A collaborative partnership to reduce preterm births in Kentucky through community-based interventions 2007-2009. Academic Press.

Ohio Perinatal Quality Collaborative Writing Committee. (2010). A statewide initiative to reduce inappropriate scheduled births at 36 0/7-38 6/7 weeks' gestation. American Journal of Obstetrics and Gynecology, 202(3), 243-e1.

Oreopoulos, P., Stabile, M., Walld, R., \& Roos, L. L. (2008). Short-, medium-, and long-term consequences of poor infant health an analysis using siblings and twins. Journal of Human Resources, 43(1), 88-138.

Royer, H. (2009). Separated at girth: US twin estimates of the effects of birth weight. American Economic Journal: Applied Economics, 1(1), 49-85.

Seyb, S. T., Berka, R. J., Socol, M. L., \& Dooley, S. L. (1999). Risk of cesarean delivery with elective induction of labor at term in nulliparous women. Obstetrics and Gynecology, 94(4), 600-607. 
Schulkind, L., \& Shapiro, T. M. (2014). What a difference a day makes: quantifying the effects of birth timing manipulation on infant health. Journal of Health Economics, 33, 139-158.

Shapiro-Mendoza, C. K., Tomashek, K. M., Kotelchuck, M., Barfield, W., Nannini, A., Weiss, J., \& Declercq, E. (2008). Effect of late-preterm birth and maternal medical conditions on newborn morbidity risk. Pediatrics, 121(2), e223-e232.

Sheiner, E., Levy, A., \& Mazor, M. (2004). Precipitate labor: higher rates of maternal complications. European Journal of Obstetrics \& Gynecology and Reproductive Biology, 116(1), 43-47.

Tita, A. T., Landon, M. B., Spong, C. Y., Lai, Y., Leveno, K. J., Varner, M. W., ... \& Sorokin, Y. (2009). Timing of elective repeat cesarean delivery at term and neonatal outcomes. New England Journal of Medicine, 360(2), 111-120. 
Figure 1: Birth Weight Measures, 1989-2013

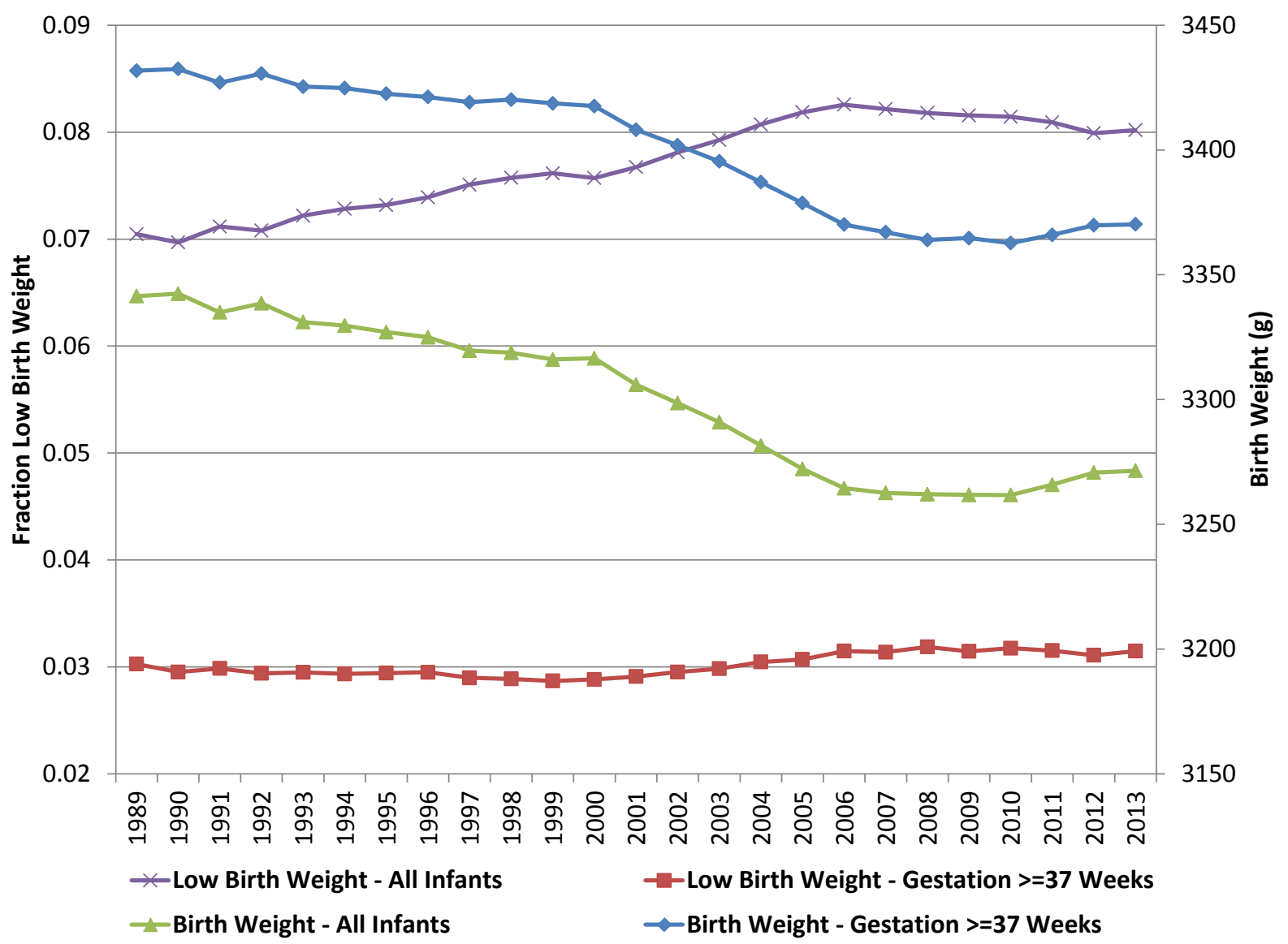

Notes: Data are from Natality Detail Files, 1989-2013. The gestation $>=37$ week sample includes only births at 37 weeks gestation or more, using clinical estimates of gestation. Low birth weight indicates a birth under 2500 grams. 
Figure 2A: Fraction of Births at 36 to 41 Weeks Gestation, 1989-2013

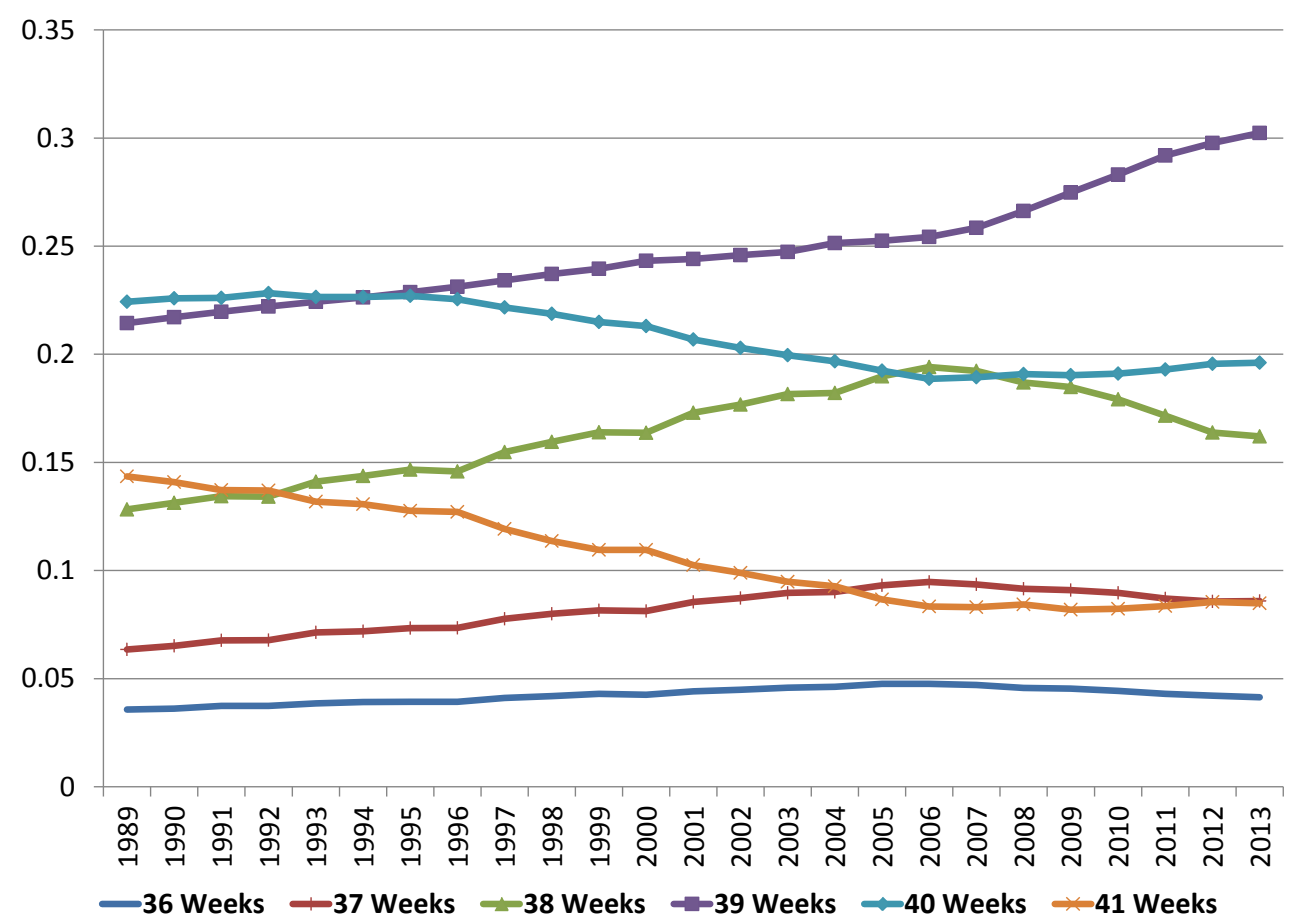

Figure 2B: Ratios for Gestation in Weeks, 1989-2013

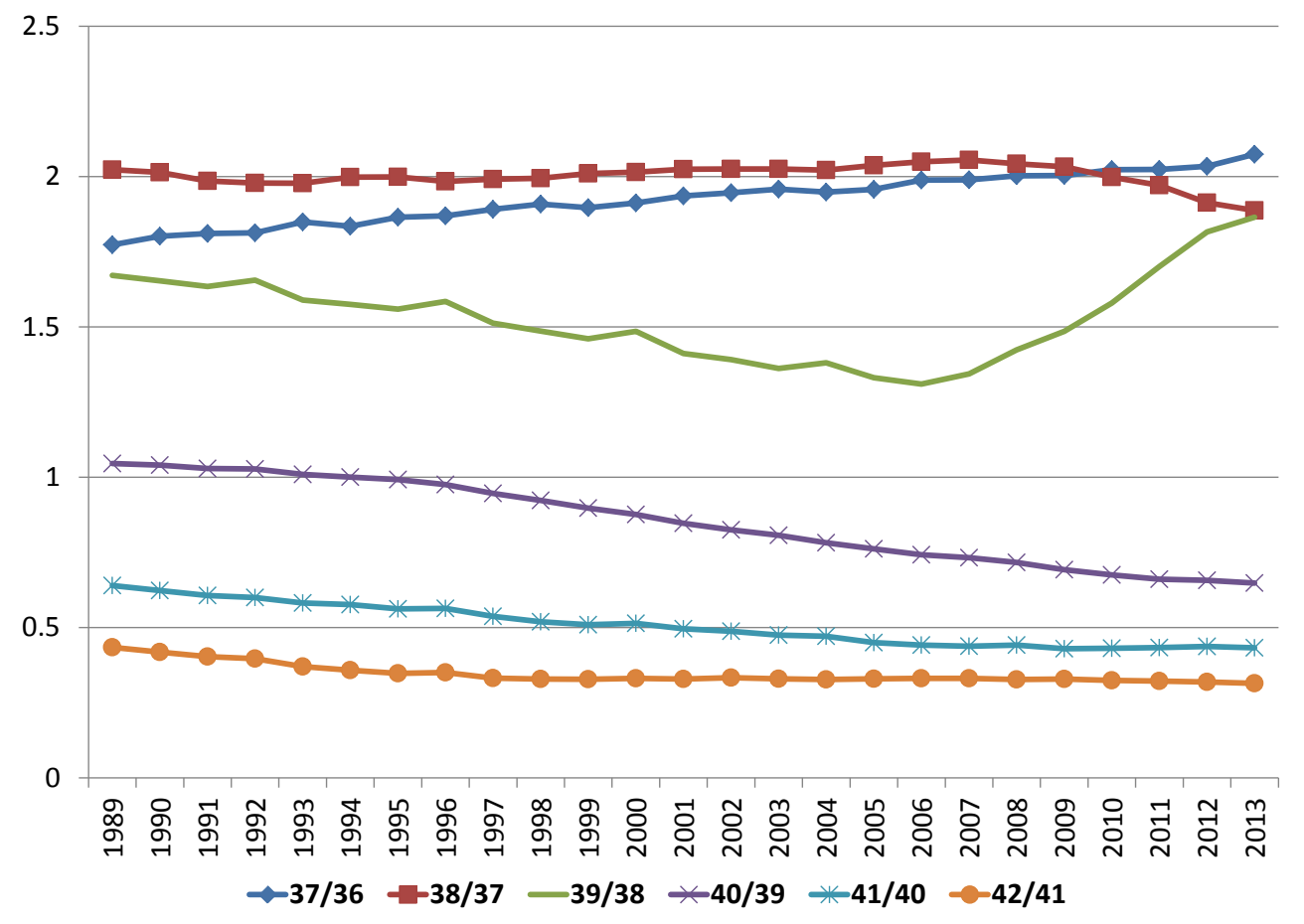

Notes: Data are from Natality Detail Files, 1989-2013. Clinical estimates of gestation are used. 
Figure 3: Fraction of Term Births Induced Before 39 Weeks, 1989-2013

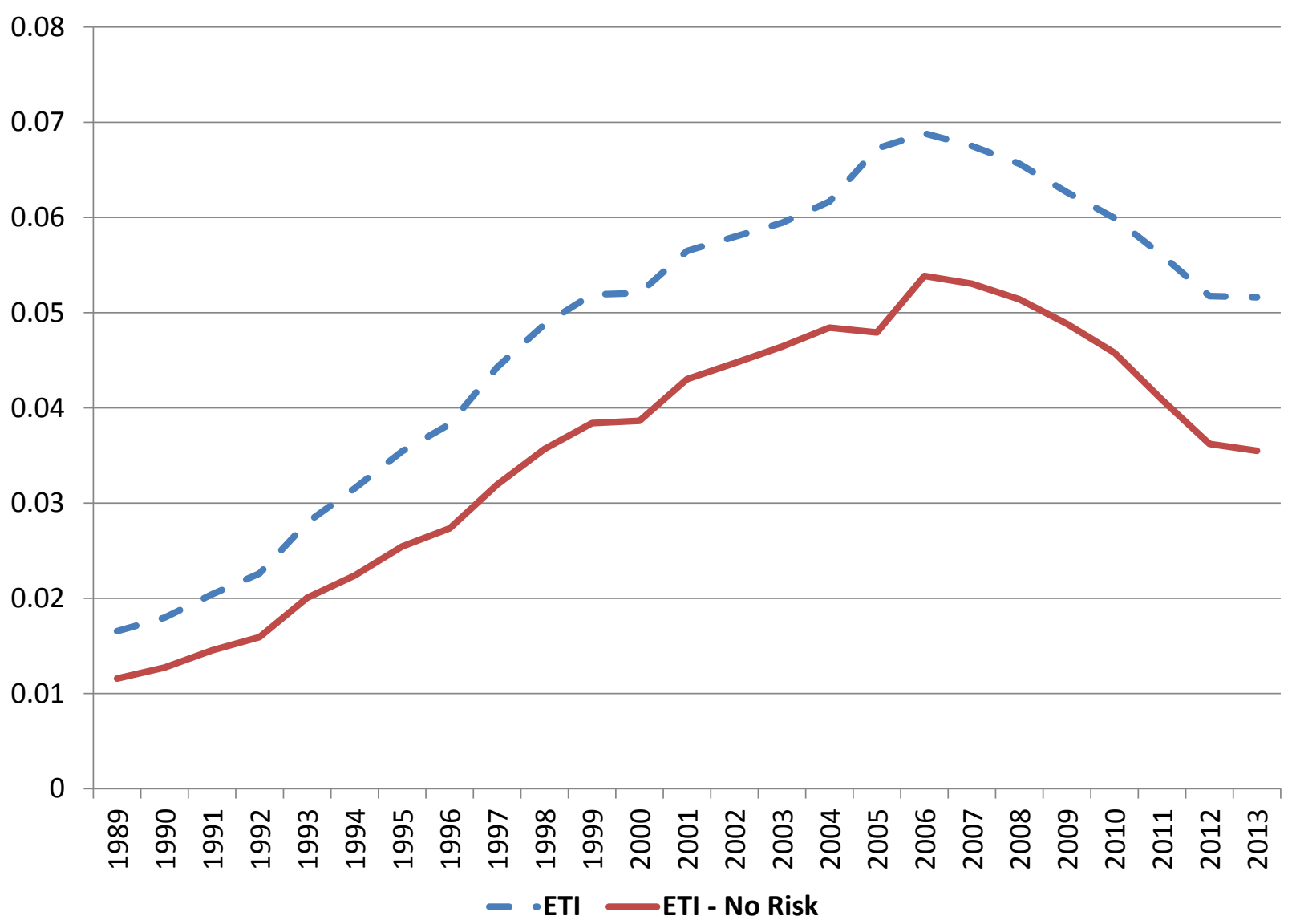

Notes: Data are from Natality Detail Files, 1989-2013. Clinical estimates of gestation are used. The dashed line gives the fraction of term births ( $>=37$ weeks) that were induced at 37 or 38 weeks (early term inductions, or ETI). The solid line gives the fraction of term births that were induced at 37 or 38 weeks without a risk factor, where risk factors include diabetes, pregnancy-related hypertension, eclampsia, previous C-section, or multiple birth. 
Figure 4: Fraction of Term Births Induced Before 39 Weeks, 1989-2013, Actual and Predicted by Demographic Characteristics

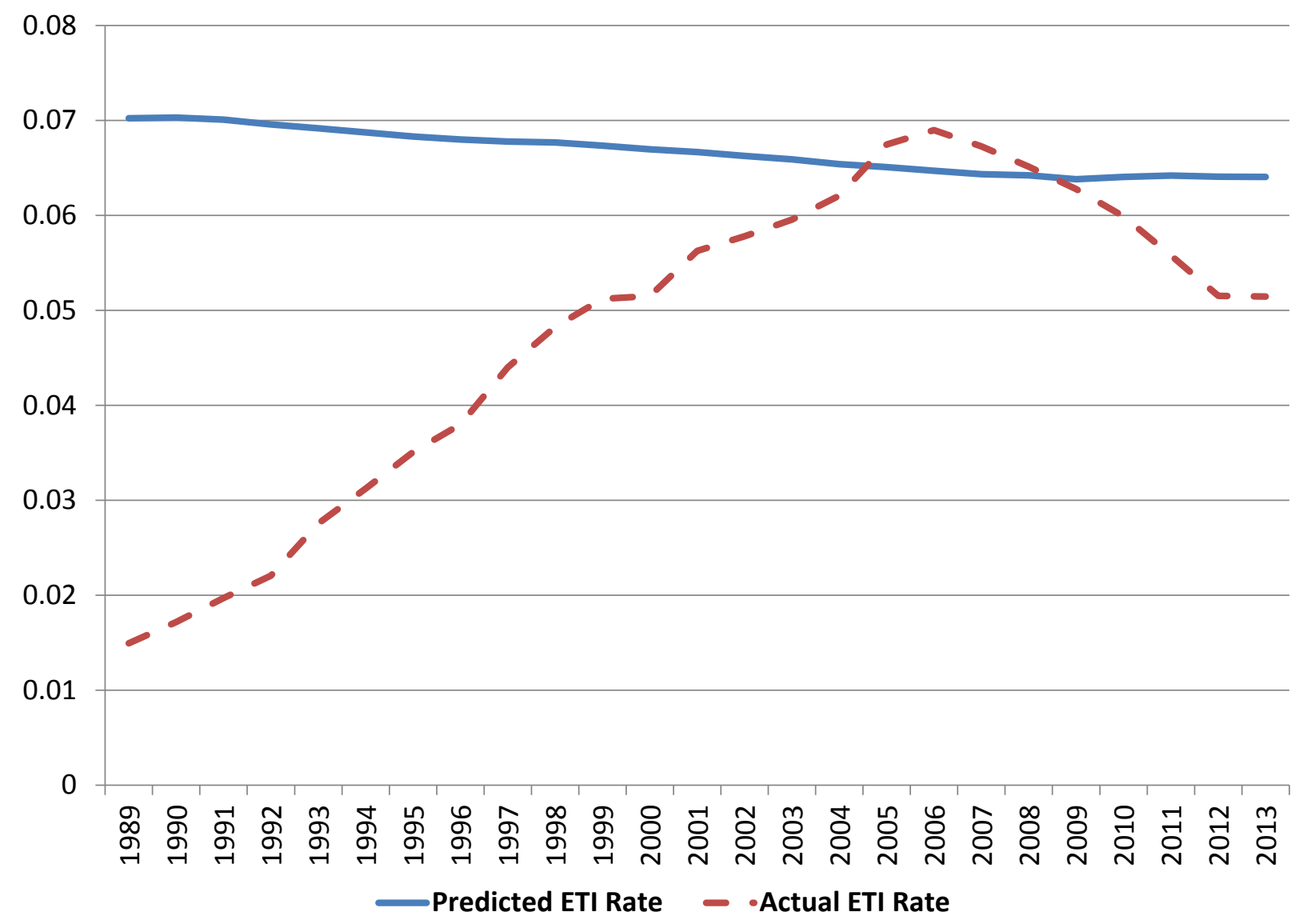

Notes: Data are from Natality Detail Files, 1989-2013. Clinical estimates of gestation are used. The dashed line gives the fraction of early term births ( $>=37$ weeks) that were induced at 37 or 38 weeks (early term inductions, or ETI). The solid line gives the predicted ETI rate for each year given the demographic composition of mothers in that year, using the coefficients from a regression of ETI on demographic characteristics in 2004/2005. See the text for more detail on how the Predicted ETI rate is calculated. 
Figure 5: Ratio of 39 Week Gestation Births to 38 Week Gestation Births Kentucky, 1989-2013

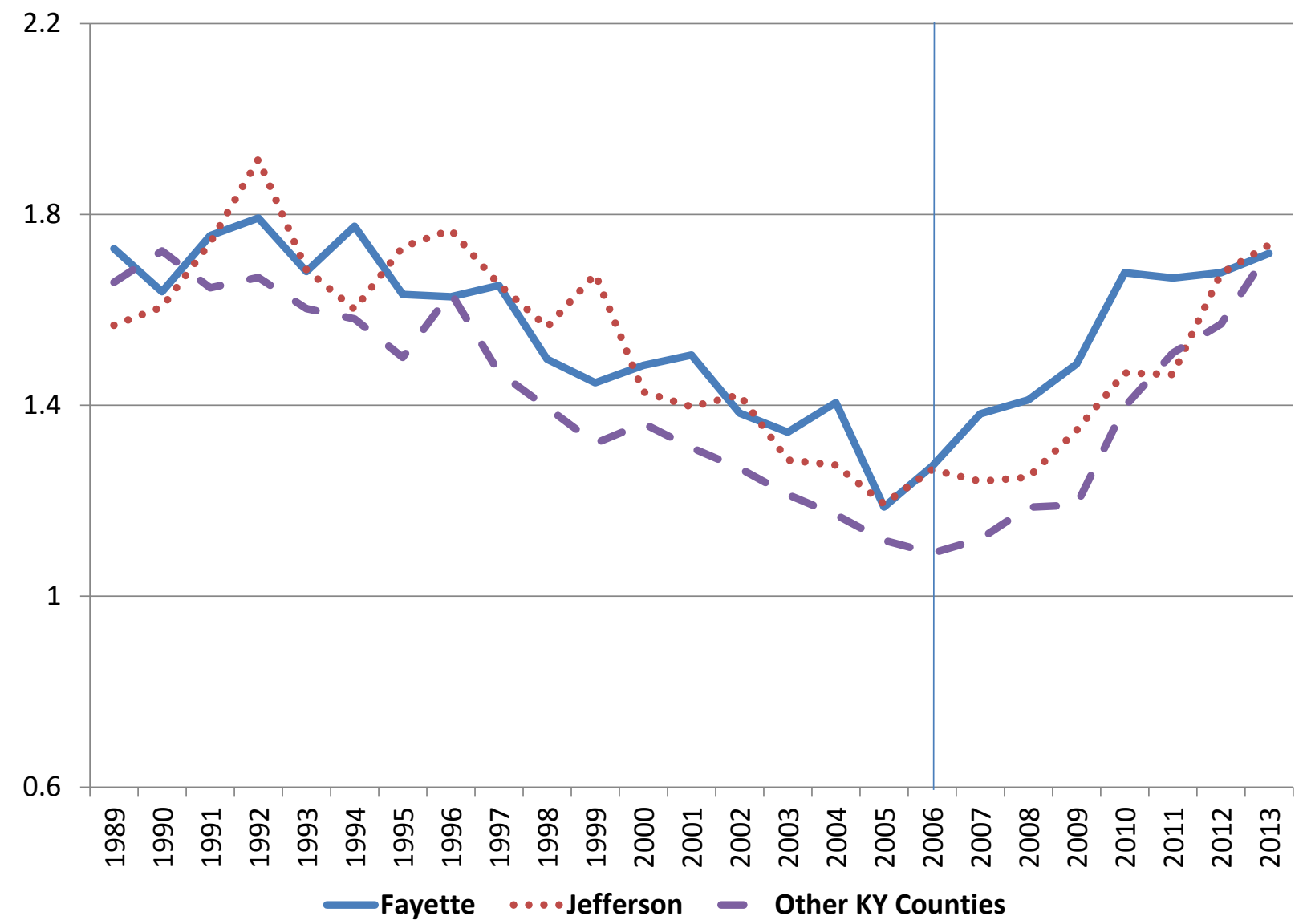

Notes: Data are from Natality Detail Files, 1989-2013. Clinical estimates of gestation are used. The HBWW Kentucky pilot was announced in 2006 and ran from 2007-2009. 
Figure 6: Fraction of Term Births Induced Before 39 Weeks, 1989-2013, For a Sample of States

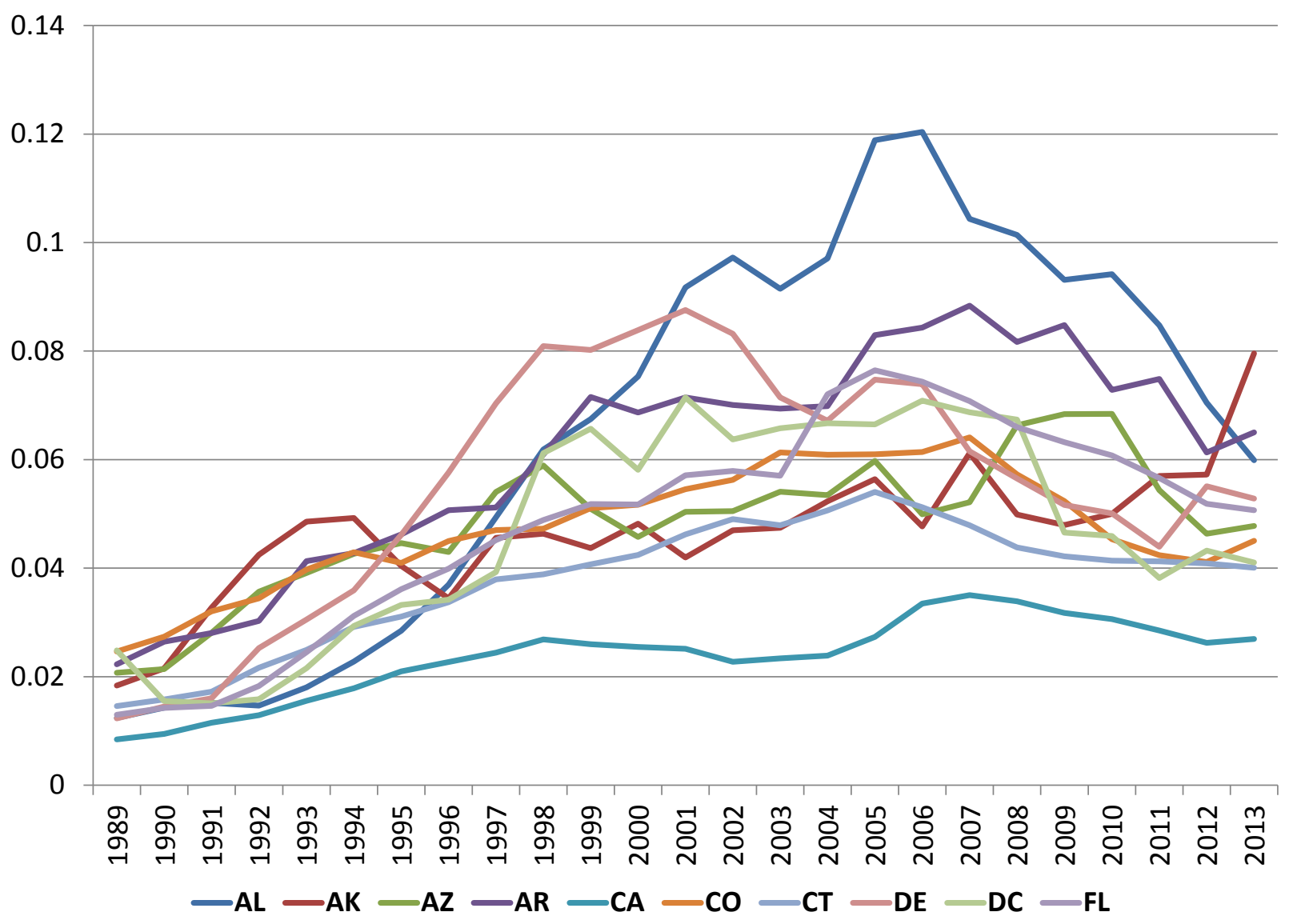

Notes: Data are from Natality Detail Files, 1989-2013. Clinical estimates of gestation are used. The figure shows the fraction of term births ( $>=37$ weeks) that were induced at 37 or 38 weeks (early term inductions, or ETI), for the first ten states in alphabetical order. 
Figure 7: Kernel Density Plots of County-Level ETI Rates

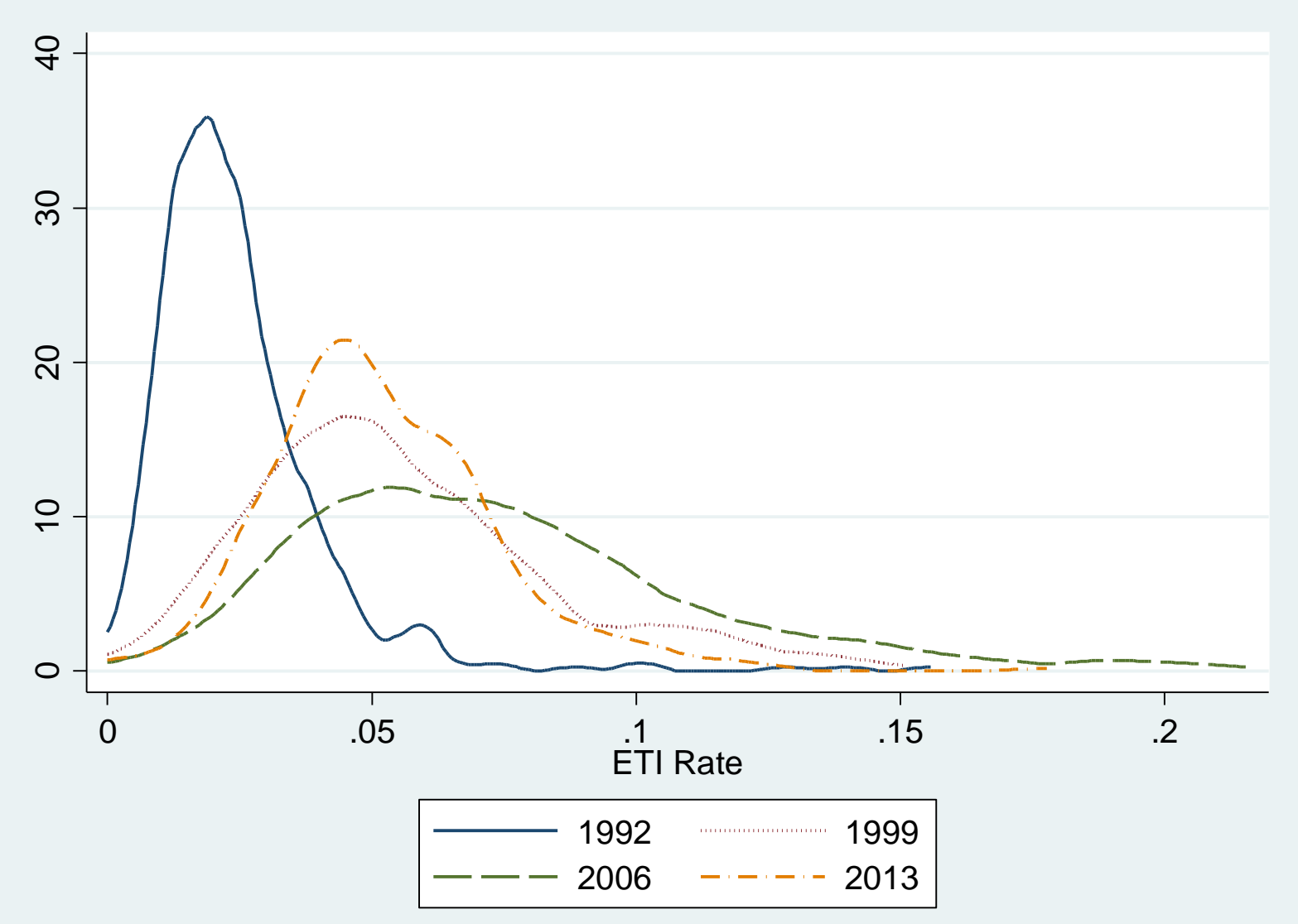

Notes: Data are from Natality Detail Files. Clinical estimates of gestation are used. The figure shows kernel density plots of ETI rates across counties, for four different years. The ETI rate is the fraction of births in the county at $>=37$ weeks that were induced in week 37 or 38 . There are 433 counties in the data each year. 
Table 1: Summary Statistics

\begin{tabular}{lcccc}
\hline & \multicolumn{2}{c}{ Individual Sample } & & \multicolumn{2}{c}{ County Sample } \\
\cline { 2 - 5 } & Mean & Std. Dev. & Mean & Std. Dev. \\
\hline \hline ETI & 0.0477 & 0.2131 & 0.0477 & 0.0290 \\
ETI - No Risk Factor & 0.0347 & 0.1830 & 0.0347 & 0.0235 \\
C-Section & 0.2421 & 0.4284 & 0.2414 & 0.0578 \\
Precipitous Labor & 0.0203 & 0.1410 & 0.0202 & 0.0159 \\
Birth Weight (g) & 3400.64 & 484.67 & 3400.09 & 57.88 \\
Low Birth Weight & 0.0298 & 0.1702 & 0.0301 & 0.0073 \\
Birth Injury & 0.0021 & 0.0455 & 0.0021 & 0.0052 \\
Required Ventilation & 0.0228 & 0.1491 & 0.0224 & 0.0335 \\
Mother's Age & 27.17 & 6.02 & 27.17 & 1.48 \\
Married & 0.6624 & 0.4729 & 0.6627 & 0.1021 \\
No Previous Birth & 0.4017 & 0.4902 & 0.4017 & 0.0425 \\
Female & 0.4895 & 0.4999 & 0.4911 & 0.0058 \\
Black, Not Hispanic & 0.1408 & 0.3478 & 0.1405 & 0.1287 \\
Hispanic & 0.2011 & 0.4008 & 0.2018 & 0.1983 \\
Other Race & 0.0707 & 0.2563 & 0.0708 & 0.0876 \\
\hline Observations & \multicolumn{2}{c}{410,459} & \multicolumn{2}{c}{10,825} \\
\hline
\end{tabular}

Notes: Data are from Natality Detail Files, 1989-2013, where births occurring before 37 weeks are dropped. The individual sample is from a $0.5 \%$ sample of these files. The county sample is from the full data set, collapsed to cells by year and county of occurrence. For the county sample, results are weighted by the number of births in the cell. ETI is an indicator for early term induction, or induction at 37 or 38 weeks. ETI - No Risk Factor indicates an ETI with no maternal risk factor identified (diabetes, pregnancy-related hypertension, eclampsia, prior C-section, or multiple birth). 
Table 2: Early term Births and Maternal and Infant Health Outcomes, County-Level Data

\begin{tabular}{|c|c|c|c|c|}
\hline \multirow[t]{3}{*}{ Independent Variable: } & \multicolumn{2}{|c|}{ STD[ETI Rate] } & \multicolumn{2}{|c|}{ STD[Ratio(39 weeks/38 weeks)] } \\
\hline & & Quadratic & & Quadratic \\
\hline & Linear Trends & Trends & Linear Trends & Trends \\
\hline \multicolumn{5}{|l|}{ Dependent Variable: } \\
\hline \multirow[t]{3}{*}{$=1$ if Cesarean Section } & -0.0001 & 0.0016 & 0.0011 & -0.0004 \\
\hline & $(0.0012)$ & $(0.0011)$ & $(0.0008)$ & $(0.0006)$ \\
\hline & 8,360 & 8,360 & 8,360 & 8,360 \\
\hline \multirow{3}{*}{$\begin{array}{c}=1 \text { if Precipitous } \\
\text { Labor }\end{array}$} & $0.0014^{* *}$ & $0.0012^{* *}$ & 0.0002 & 0.0002 \\
\hline & $(0.0006)$ & $(0.0006)$ & $(0.0005)$ & $(0.0004)$ \\
\hline & 9,465 & 9,465 & 9,465 & 9,465 \\
\hline \multirow[t]{3}{*}{ Birth Weight (g) } & $-9.6105^{* * *}$ & $-7.9619 * * *$ & $8.8157 * * *$ & $6.5587 * * *$ \\
\hline & $(0.7992)$ & $(0.7283)$ & $(0.6742)$ & $(0.5569)$ \\
\hline & 9,465 & 9,465 & 9,465 & 9,465 \\
\hline \multirow{3}{*}{$\begin{array}{c}=1 \text { if Low Birth } \\
\text { Weight }\end{array}$} & $0.0005^{* * *}$ & $0.0006^{* * *}$ & $-0.0006 * * *$ & $-0.0004 * * *$ \\
\hline & $(0.0001)$ & $(0.0002)$ & $(0.0001)$ & $(0.0001)$ \\
\hline & 9,465 & 9,465 & 9,484 & 9,484 \\
\hline \multirow[t]{3}{*}{$=1$ if Birth Injury } & 0.0014 & $0.0012^{*}$ & -0.0002 & 0.0000 \\
\hline & $(0.0009)$ & $(0.0007)$ & $(0.0003)$ & $(0.0002)$ \\
\hline & 8,385 & 8,385 & 8,385 & 8,385 \\
\hline \multirow{3}{*}{$\begin{array}{r}=1 \text { if Requires } \\
\text { Ventilation }\end{array}$} & 0.0010 & $0.0015^{*}$ & -0.0001 & -0.0002 \\
\hline & $(0.0009)$ & $(0.0009)$ & $(0.0009)$ & $(0.0007)$ \\
\hline & 8,593 & 8,593 & 8,593 & 8,593 \\
\hline
\end{tabular}

Notes: Data are from Natality Detail Files, 1989-2013, where births occurring before 37 weeks are dropped. The data are collapsed to cells by year and county of occurrence, and results are weighted by the number of births in the cell. The ETI rate is the fraction of births in the county that were early term inductions, or inductions at 37 or 38 weeks. Ratio(39weeks/38weeks) is the ratio of births in the county at 39 weeks gestation to births at 38 weeks. These variables are standardized to have mean zero and standard deviation of one. Each column is a separate regression, which also includes year and county fixed effects, fraction of births in the county under 33 weeks gestation, controls for average mother's age, education level, fraction married, fraction with no prior birth, fraction female, fraction Black, Hispanic, or other, and the following ratios of weeks gestation: 36/35, 35/34, 34/33. Regressions also include either linear or quadratic county-specific time trends, as indicated above the columns. Standard errors are clustered at the county level and are in parentheses; below this is the number of observations. Asterisks indicate statistical significance at $* 10 \%$, ** 5\%, and $* * * 1 \%$ levels. 
Table 3: Early term Births and Maternal and Infant Health Outcomes, OLS and IV Estimates Using Individual-Level Data

\begin{tabular}{|c|c|c|c|c|}
\hline & \multicolumn{2}{|c|}{ Linear Trends } & \multicolumn{2}{|c|}{ Quadratic Trends } \\
\hline & OLS & IV & OLS & IV \\
\hline \multicolumn{5}{|l|}{ Dependent Variable: } \\
\hline \multirow{3}{*}{$\begin{array}{l}=1 \text { if Cesarean } \\
\text { Section }\end{array}$} & $-0.0853 * * *$ & 0.0351 & $-0.0856 * * *$ & -0.0104 \\
\hline & $(0.0046)$ & $(0.0678)$ & $(0.0046)$ & $(0.0768)$ \\
\hline & 282,305 & 282,305 & 282,305 & 282,305 \\
\hline \multirow{3}{*}{$\begin{array}{c}=1 \text { if Precipitous } \\
\text { Labor }\end{array}$} & $-0.0035^{* * *}$ & $0.0717 * *$ & $-0.0034 * * *$ & $0.0930 * * *$ \\
\hline & $(0.0011)$ & $(0.0299)$ & $(0.0011)$ & $(0.0336)$ \\
\hline & 321,566 & 321,566 & 321,566 & 321,566 \\
\hline \multirow[t]{3}{*}{ Birth Weight (g) } & $-179.9202^{* * *}$ & $-250.8800^{* * *}$ & $-179.9868^{* * *}$ & $-218.2425^{* * *}$ \\
\hline & $(5.564)$ & $(64.5762)$ & $(5.576)$ & (81.9021) \\
\hline & 322,907 & 322,907 & 322,907 & 322,907 \\
\hline \multirow{3}{*}{$\begin{array}{c}=1 \text { if Low Birth } \\
\text { Weight }\end{array}$} & $0.0443^{* * *}$ & 0.0055 & $0.0445^{* * *}$ & 0.0153 \\
\hline & $(0.0028)$ & $(0.0267)$ & $(0.0028)$ & $(0.0302)$ \\
\hline & 322,907 & 322,907 & 322,907 & 322,907 \\
\hline \multirow[t]{3}{*}{$=1$ if Birth Injury } & $0.0011^{* *}$ & $0.0160 * *$ & $0.0011^{* *}$ & $0.0182^{* *}$ \\
\hline & $(0.0005)$ & $(0.0078)$ & $(0.0005)$ & $(0.0092)$ \\
\hline & 278,868 & 278,868 & 278,868 & 278,868 \\
\hline \multirow{3}{*}{$\begin{array}{r}=1 \text { if Requires } \\
\text { Ventilation }\end{array}$} & $0.0056 * * *$ & $0.0837 * *$ & $0.0056^{* * *}$ & $0.0988^{* *}$ \\
\hline & $(0.0015)$ & $(0.0419)$ & $(0.0015)$ & $(0.0481)$ \\
\hline & 286,458 & 286,458 & 286,458 & 286,458 \\
\hline
\end{tabular}

Notes: Data are from Natality Detail Files, 1989-2013, where births occurring before 37 weeks are dropped. The individual sample is from a $0.5 \%$ sample of these files. ETI is an indicator for early term induction, or induction at 37 or 38 weeks. Each column is a separate regression, which also includes year and county fixed effects, fraction of births in the county under 33 weeks gestation, controls for average mother's age, education level, fraction married, fraction with no prior birth, fraction female, fraction Black, Hispanic, or other, and the following ratios of weeks gestation: 36/35, 35/34, 34/33. Regressions also include either linear or quadratic county-specific time trends, as indicated above the columns. For the IV regressions, the instruments are ETI rate and 39/38 weeks gestation ratio in the county of occurrence. Standard errors are clustered at the county level and are in parentheses; below this is the number of observations. Asterisks indicate statistical significance at $* 10 \%, * * 5 \%$, and $* * * 1 \%$ levels. 


\section{Appendix Table 1: ACOG Committee Opinions and Recommendations Timeline}

\begin{tabular}{|c|c|}
\hline 1999 & Practice Bulletin Number 10 "Induction of Labor" (replaced by Practice \\
\hline (November) & Bulletin No. 107, August 2009) \\
\hline 1999 & Committee Opinion No. 228 (replaced by Practice Bulletin No. 107, August \\
\hline (November) & 2009) \\
\hline 2000 (December) & $\begin{array}{l}\text { Committee Opinion No. } 248 \text { (replaced by Practice Bulletin No. 107, August } \\
\text { 2009) }\end{array}$ \\
\hline 2003 (May) & $\begin{array}{l}\text { Committee Opinion No. } 283 \text { (replaced by Practice Bulletin No. 107, August } \\
\text { 2009) }\end{array}$ \\
\hline 2007 (December) & $\begin{array}{l}\text { Committee Opinion No. 394, "Caesarean delivery on maternal request." } \\
\text { Recommends no delivery before } 39 \text { weeks gestation unless there is } \\
\text { documentation of lung maturity. (no longer current) }\end{array}$ \\
\hline 2009 (August) & Practice Bulletin Number 107, August 2009 "Induction of Labor" \\
\hline reaffirme & $\begin{array}{l}\text { Suggests no induction unless medically indicated before } 39 \text { weeks gestation. } \\
\text { Provides and emphasizes lists of medical tests to be used to determine whether } \\
\text { gestation is } 39 \text { weeks or greater. }\end{array}$ \\
\hline 2013 (April), & Committee Opinion No. 559, "Caesarean Delivery on Maternal Request" \\
\hline reaffirmed 2015 & $\begin{array}{l}\text { Recommend against maternal request for Caesarean delivery, especially for } \\
\text { delivery before } 39 \text { weeks gestation. }\end{array}$ \\
\hline $\begin{array}{l}2013 \text { (April), } \\
\text { reaffirmed } 2015\end{array}$ & $\begin{array}{l}\text { Committee Opinion No. 561, "Nonmedically-Indicated Early Term Deliveries," } \\
\text { Recommends no delivery before } 39 \text { weeks gestation unless medically indicated } \\
\text { and provides evidence on negative health consequences for infants born near } \\
\text { term. }\end{array}$ \\
\hline
\end{tabular}

Source: American College of Obstetricians and Gynecologists. Practice Bulletins and Committee Opinions are defined as current relative to the November 2015 lists of these recommendations.

Committee Opinions: http://www.acog.org/-/media/List-of-Titles/COListOfTitles.pdf?la=en downloaded on 10-28-15

Practice Bulletins: http://www.acog.org/-/media/List-of-Titles/PBListOfTitles.pdf?la=en downloaded on 10-28-15 
Appendix Table 2: Medicaid Policies on Early Elective Deliveries (EED)

\begin{tabular}{|c|c|c|c|c|}
\hline State & Incentive Program & Refuse Payment & $\begin{array}{c}\text { Collaborative } \\
\text { Strategy }\end{array}$ & Hard Stop \\
\hline $\mathrm{AL}$ & & & 2012 & \\
\hline AR & 2007, 2012 & & 2007,2011 & \\
\hline CA & & & 2010 & \\
\hline FL & & & 2011 & \\
\hline GA & & 2013 & & \\
\hline $\mathrm{KY}$ & & & 2007 & \\
\hline LA & 2012 & & 2011 & \\
\hline $\mathrm{MD}$ & & & 2011 & \\
\hline MI & & & 2012 & 2013 \\
\hline $\mathrm{MN}$ & & & 2012 & 2012 \\
\hline MS & & & 2012 & \\
\hline NM & & 2013 & & \\
\hline NY & & 2012 & & \\
\hline $\mathrm{NC}$ & 2011 & & 2009, 2010 & 2013 \\
\hline $\mathrm{OH}$ & & & 2008 & \\
\hline OK & & & 2011 & \\
\hline OR & & & & 2011 \\
\hline SC & & 2013 & 2011 & \\
\hline $\mathrm{TN}$ & 2011 & & 2012 & 2012 \\
\hline TX & & 2011 & 2011 & \\
\hline WA & 2009 & & & \\
\hline
\end{tabular}

Note: Policies obtained from "Reducing Early Elective Deliveries in Medicaid and CHIP," available at medicaid.gov. Dates are from state policy websites. Sources available upon request. Incentive programs provide payment incentives for the reduction of EED. "Refuse payment" indicates that the state will not reimburse providers for EED without a medical indication. Collaborative strategies are efforts coordinated by providers within the state. "Hard stop" policies prohibit the use of EED without medical indication, and are put in place by law or by collaboration. 